\title{
Hypokalemic Paralysis as a Presenting Manifestation of Primary Sjögren's Syndrome Accompanied by Vitamin D Deficiency
}

\author{
Chen-Yi Liao, Chih-Chiang Wang, I-Hung Chen, \\ Jeng-Chuan Shiang, Mei-Yu Liu and Ming-Kai Tsai
}

\begin{abstract}
Primary Sjögren's syndrome (pSS) is a chronic autoimmune disease characterized by progressive lymphocyte infiltration of the exocrine glands. Overt or latent renal tubular acidosis (RTA) is a common extraglandular manifestation of pSS.Vitamin D deficiency is associated with autoimmune disorders; however, the potential correlation between pSS and vitamin D deficiency is rarely discussed. The current patient presented with distal RTA, hypocalcemia, and hypophosphatemia that were found to be secondary to both vitamin D deficiency and pSS. In patients diagnosed with both distal RTA and vitamin D deficiency, clinicians should consider autoimmune diseases such as pSS, as a possible underlying etiology.
\end{abstract}

Key words: Sjögren's syndrome, vitamin D deficiency, renal tubular acidosis, hypokalemic paralysis, autoimmune diseases

(Intern Med 52: 2351-2353, 2013)

(DOI: 10.2169/internalmedicine.52.0899)

\section{Introduction}

Primary Sjögren's syndrome (pSS) is a disease of the exocrine glands that presents with dry eyes and mouth. Extraexocrine organ systems may also be involved, including the skin, lungs, gastrointestinal tract, nervous system, muscular skeletal apparatus, and kidneys (1). The reported rate of renal involvement in patients with pSS is variable, ranging from $2-67 \%$ (2). The spectrum of renal disease includes interstitial nephritis, renal tubular acidosis (RTA), tubular proteinuria, nephrogenic diabetes insipidus, glomerulonephritis, and renal failure (3). The most common manifestations are related to tubular dysfunction resulting from chronic interstitial nephritis with prominent $\mathrm{CD}^{4+} \mathrm{T}$ lymphocyte infiltration (4). RTA is the most common finding in Chinese pSS patients with renal involvement (5). Furthermore, hypokalemia is the most common electrolyte abnormality in RTA patients. The mechanism of underlying pSSrelated RTA can be attributed to the complete absence of HATPase pumps in the intercalated cells (6) or autoantibodies directed against carbonic anhydrase II, which is associated with an impaired distal tubular transporter function (7). Abnormal vitamin D metabolism has been reported in pSS patients (8). However, the potential correlations between vitamin D deficiency and pSS have not been thoroughly investigated. We herein present a case of pSS with both RTA and vitamin D deficiency.

\section{Case Report}

A 49-year-old Chinese man presented to the emergency department with paralysis of all extremities upon awakening in the morning. His past medical records revealed intermittent, periodic, hypokalemic paralysis. Initially, no sicca symptoms were reported. Under the assumption of a diagnosis of RTA, additional drug and toxin surveys were performed at our nephrology outpatient department, resulting in negative findings. The patient had taken potassium citrate (10 gm QD) and spironolactone (25 mg bid) for hypokalemic paralysis. However, he did not attend follow-up visits for four months prior to admission, due to his busy schedule 
Table. Laboratory Parameters When at OPD and Admission

\begin{tabular}{|c|c|c|}
\hline & OPD & Admission \\
\hline $\mathrm{pH}(7.35-7.45)$ & 7.266 & 7.281 \\
\hline $\mathrm{HCO}_{3}^{-}(22-28 \mathrm{mmol} / \mathrm{L})$ & 18.8 & 21.0 \\
\hline $\mathrm{Na}^{+} \quad(136-145 \mathrm{mmol} / \mathrm{L})$ & 144.2 & 141.5 \\
\hline $\mathrm{K}^{+} \quad(3.5-5.1 \mathrm{mmol} / \mathrm{L})$ & 2.7 & 1.9 \\
\hline $\mathrm{Cl}^{-} \quad(98-107 \mathrm{mmol} / \mathrm{L})$ & 114.4 & 110.7 \\
\hline $\mathrm{Ca}^{2+}(8.4-10.2 \mathrm{mg} / \mathrm{dL})$ & 7.8 & 7.9 \\
\hline Phosphate(2.4-4.5mg/dL) & 2.1 & 1.6 \\
\hline Uric $\operatorname{acid}(3.4-7 \mathrm{mg} / \mathrm{dL})$ & 3.3 & 5.2 \\
\hline Glucose $(70-105 \mathrm{mg} / \mathrm{dL})$ & 111 & 94 \\
\hline BUN (7-20mg/dL) & 14 & 15 \\
\hline Creatinine $(0.7-1.2 \mathrm{mg} / \mathrm{dL})$ & 1.1 & 1.4 \\
\hline Total protein $(6.4-8.3 \mathrm{mg} / \mathrm{dL})$ & 6.5 & 6.9 \\
\hline Albumin $(3.4-4.8 \mathrm{mg} / \mathrm{dL})$ & 3.3 & 3.9 \\
\hline $\mathrm{A} / \mathrm{G}$ ratio $(1.2-2.4)$ & 1.0 & 1.3 \\
\hline ANA & $1: 320$ & $1: 2,560$ \\
\hline Rheumatoid factor $(0-15 \mathrm{IU} / \mathrm{mL})$ & 23.4 & 16.8 \\
\hline $\begin{array}{l}\text { AntiRo/La }(<7 \mathrm{U} / \mathrm{mL} \text {; } \\
\text { negative; }>10 \mathrm{U} / \mathrm{mL} ; \text { positive })\end{array}$ & None & $>240 />320$ \\
\hline $\mathrm{C} 3(86 \sim 160 \mathrm{mg} / \mathrm{dL})$ & None & 92 \\
\hline $\mathrm{C} 4(17 \sim 45 \mathrm{mg} / \mathrm{dL})$ & None & 23 \\
\hline $\operatorname{IgG}(750-1,560 \mathrm{mg} / \mathrm{dL})$ & None & None \\
\hline \multicolumn{3}{|l|}{ Urinalysis } \\
\hline Glucose(-) & $(-)$ & $(-)$ \\
\hline Protein(-) & $(-)$ & $(-)$ \\
\hline Urine NAG & None & None \\
\hline
\end{tabular}

as a marble stone worker. The patient reported normal dietary habits with three meals per day consisting predominantly of rice. He claimed no history of vomiting, diarrhea, use of Chinese herbs, chemotherapy agents, or steroids. He also did not have hyperthyroidism.

On admission, the blood cell count was within the normal range. A urinalysis revealed a $\mathrm{pH}$ of 7.0 with protein (-). Profound hypokalemia $\left(\mathrm{K}^{+}, 1.9 \mathrm{mmol} / \mathrm{L}\right)$ with renal $\mathrm{K}^{+}$wasting (urine $\mathrm{K}^{+}$: $\mathrm{Cr}$ ratio, $4.44 \mathrm{mmol}$ : mmol; transtubular potassium concentration gradient, TTKG 8.2) was the most prominent abnormality.

Hyperchloremic metabolic acidosis associated with a positive urinary anion gap (low ammonium excretion), alkaline urinary $\mathrm{pH}(>5.5)$, and renal stones strongly suggested the presence of distal RTA. In addition to an abnormal renal function (urea nitrogen, $15 \mathrm{mg} / \mathrm{dL}$; creatinine, $1.4 \mathrm{mg} / \mathrm{dL}$ ), the patient also had hypophosphatemia $(1.6 \mathrm{mg} / \mathrm{dL})$ with hyperphosphaturia $\left(\mathrm{FE}_{\mathrm{PO} 4}, 9.7 \%\right)$ and hypocalcemia $(7.9 \mathrm{mg} /$ dL). The laboratory findings are shown in Table. An electrocardiogram disclosed no obvious abnormalities. Abdominal sonography revealed multiple bilateral renal stones. The patient's muscle strength recoverd following aggressive $\mathrm{KCl}$ supplementation (a rate of $10 \mathrm{mEq} / \mathrm{h}$ for 24 hours), after which he received oral potassium citrate $(45 \mathrm{mEq} / \mathrm{d})$.

Due to hypophosphatemia $(1.6 \mathrm{mg} / \mathrm{dL})$ accompanied by hypocalcemia $(7.9 \mathrm{mg} / \mathrm{dL})$ and mildly elevated iPTH $(92.2$ $\mathrm{pg} / \mathrm{mL}$ ), a vitamin D test was performed, which showed a 25-hydroxyvitamin D [25(OH)D] level of $16.9 \mathrm{ng} / \mathrm{mL}$ (normal range, $>30 \mathrm{ng} / \mathrm{mL}$ ), thereby confirming the diagnosis of vitamin $\mathrm{D}$ deficiency. A thorough investigation of the underlying cause revealed xerostomia (the need for liquids to swallow dry foods), xerophthalmia (a foreign body sensation in the eyes), positive anti-Ro and anti-La antibodies, a high antinuclear antibodies (ANA) titer (1:2,560, speckled), delayed saliva excretion on salivary scintigraphy, and a positive Schirmer's test $(<5 \mathrm{~mm} / 5 \mathrm{~min})$. Based on these results, the patient met the diagnostic criteria for pSS and was placed on potassium citrate $(45 \mathrm{mEq} / \mathrm{d})$ and active vitamin D3 $(0.25 \mu \mathrm{g} / \mathrm{d})$ therapy to treat the hypokalemia and vitamin $\mathrm{D}$ deficiency, respectively. The patient refused additional steroids, chemotherapy, and renal biopsies. He experienced no further sicca symptoms or paralysis during outpatient department followe-up treatment with potassium citrate and active vitamin D3.

\section{Discussion}

The present patient met the American-European classification criteria for $\mathrm{pSS}$. Ingested and cutaneously produced vitamin D is rapidly converted to 25-hydroxyvitamin D [25 $(\mathrm{OH}) \mathrm{D}$ or calcidiol]; however, only a fraction of $25(\mathrm{OH}) \mathrm{D}$ is converted to its active metabolite, 1,25-dihydroxyvitamin D $\left[1,25(\mathrm{OH})_{2} \mathrm{D}\right.$; calcitriol]. Therefore, measuring the total 25 $(\mathrm{OH}) \mathrm{D}$ level is the best test for assessing the amount of stored vitamin D. Vitamin D deficiency is defined as a 25 $(\mathrm{OH}) \mathrm{D}$ level of $<20 \mathrm{ng} / \mathrm{mL}(9)$. In our case, the $25(\mathrm{OH}) \mathrm{D}$ level was $16.9 \mathrm{ng} / \mathrm{mL}$, confirming the diagnosis of vitamin D deficiency.

The causes of vitamin D deficiency include reduced synthesis of vitamin D in the skin (caused by sunscreen use, skin pigmentation, aging, seasonal weather, latitude, time of day, and skin grafts used to treat burns), decreased bioavailability (malabsorption), increased catabolism (often caused by medications, such as glucocorticoids or anticonvulsants), breast feeding, decreased synthesis of $25(\mathrm{OH}) \mathrm{D}$ due to liver failure, increased urinary excretion of $25(\mathrm{OH}) \mathrm{D}$ (caused by nephrotic syndrome), and acquired disorders (such as tumorinduced osteomalacia, primary hyperparathyroidism, granulomatous disorders, and hyperthyroidism). Some heritable forms of rickets include: pseudo-vitamin D deficiency rickets (vitamin D-dependent rickets type 1), autosomal dominant hypophosphatemic rickets, and X-linked hypophosphatemic rickets. All of these potential causes of vitamin D deficiency were excluded in this case. Another mechanism, in which $25(\mathrm{OH}) \mathrm{D}$ is metabolized by macrophages resulting in a decreased $25(\mathrm{OH}) \mathrm{D}$ level, associated with autoimmune disorders $(8,9)$. Like vitamin D deficiency, RTA has hundreds of possible etiologies. It is possible for two unrelated, distinct diseases to exist in a single patient. For concurrent RTA and vitamin D deficiency, only a few potential causes, including autoimmune disease and Fanconi's syndrome, have been described. Fanconi's syndrome was excluded in this case due to the lack of proteinuria, aminoaciduria, and glycosuria and the normal uric acid level. A diagnosis of pSS with RTA associated with vitamin D deficiency was therefore highly probable in this case.

Abnormal vitamin D metabolism has rarely been reported 
in pSS patients (8). Vitamin D may play a role in the pathogenic process and disease expression of pSS and is generally an important environmental factor that can increase the prevalence of certain autoimmune diseases, including multiple sclerosis, systemic lupus erythematous, rheumatoid arthritis, insulin-dependent diabetes mellitus, and inflammatory bowel disease $(9,10)$. Zold et al. reported that, in their study, individuals with undifferentiated connective tissue disorders who progressed to rheumatoid arthritis (34.2\%), lupus (17.1\%), Sjögren's syndrome (17.1\%), or mixed connective tissue disease $(17.1 \%)$ had lower vitamin D levels than individuals who did not progress beyond the undifferentiated connective tissue disease stage (11). In recent years, the discovery of the nuclear vitamin D receptor (VDR) expression in immune cells and the finding that some immune cells can produce the vitamin $\mathrm{D}$ hormone have suggested that vitamin $\mathrm{D}$ possesses immunoregulatory properties $(9,12)$. Alternatively, pSS, which results from polyclonal B cell activation, may itself have contributed to the low concentration of 25 $(\mathrm{OH}) \mathrm{D}$ observed in this case because $25(\mathrm{OH}) \mathrm{D}$ is metabolized in activated monocytes and consumed by activated lymphocytes by binding to vitamin $\mathrm{D}$ receptors (8). The relationship between vitamin D deficiency and autoimmune disease brings to mind the "chicken and egg" scenario: which comes first, vitamin D deficiency or autoimmunity? Currently, the evidence remains inconclusive.

Patients with concurrent RTA, hypocalcemia, and hypophosphatemia should undergo vitamin D testing. If vitamin D deficiency is confirmed in patients with RTA, further autoimmune testing should be performed due to the close correlation between vitamin D deficiency and autoimmunity. Vitamin D deficiency is linked to the disease activity in new cases of systemic lupus erythematosus and warrants prompt vitamin D supplementation (13). Vitamin D treatment has been shown to improve in autoimmune diseases, including rheumatoid arthritis, multiple sclerosis, and psoriasis $(12,14)$. Concurrent pSS and vitamin D deficiency increases the risk for peripheral neuropathy, lymphoma, osteomalacia, and even multiple bone fractures $(15,16)$. The mainstay of treatment for pSS with vitamin D deficiency is the maintenance of the acid-base and electrolyte balance, with further treatment aimed at ameliorating the underling disease. Potassium citrate and active vitamin $\mathrm{D}_{3}$ can be administered to correct metabolic acidosis, hypokalemia, and hypophosphatemia and prevent further nephrocalcinosis.

Based on our case, we conclude that patients diagnosed with both RTA and vitamin D deficiency should be considered highly likely to have some type of autoimmune disease, such as pSS. Early diagnosis lead to the more rapid initiation of the correct course of treatment, including vitamin D supplementation, and improve patient outcomes.

The authors state that they have no Conflict of Interest (COI).

\section{References}

1. Mitsias DI, Kapsogeorgou EK, Moutsopoulos HM. Sjögren's syndrome: why autoimmune epithelitis? Oral Dis 12: 523-532, 2006.

2. Ren H, Wang WM, Chen XN, et al. Renal involvement and followup of 130 patients with primary Sjögren's syndrome. J Rheumatol 35: 278-284, 2008.

3. Bossini N, Savoldi S, Franceschini F, et al. Clinical and morphological features of kidney involvement in primary Sjögren's syndrome. Nephrol Dial Transplant 16: 2328-2336, 2001.

4. Enestrom S, Denneberg T, Eriksson P. Histopathology of renal biopsies with correlation to clinical findings in primary Sjögren's syndrome. Clin Exp Rheumatol 13: 697-703, 1995.

5. Yang J, Li X, Huang Q. Renal involvement in primary Sjögren's syndrome: a clinicopathological study of 26 cases. Zhonghua Nei Ke Za Zhi 36: 28-31, 1997.

6. DeFranco PE, Haragsim L, Schmitz PG, et al. Absence of vacuolar $\mathrm{H}(+)$-ATPase pump in the collecting duct of a patient with hypokalemic distal renal tubular acidosis and Sjögren's syndrome. J Am Soc Nephrol 6: 295-301, 1995.

7. Takemoto F, Hoshino J, Sawa N, et al. Autoantibodies against carbonic anhydrase II are increased in renal tubular acidosis associated with Sjögren's syndrome. Am J Med 118: 181, 2005.

8. Müller K, Oxholm P, Sørensen OH, et al. Abnormal vitamin D3 metabolism in patients with primary Sjögren's syndrome. Ann Rheum Dis 49: 682-684, 1990.

9. Holick MF. Vitamin D deficiency. N Engl J Med 357: 266-281, 2007.

10. Cutolo M. Vitamin D or hormone D deficiency in autoimmune rheumatic diseases, including undifferentiated connective tissue disease. Arthritis Res Ther 10: 123, 2008.

11. Zold E, Szodoray P, Gaal J, et al. Vitamin D deficiency in undifferentiated connective tissue disease. Arthritis Res Ther 10: R123, 2008.

12. Adorini L. Intervention in autoimmunity: the potential of vitamin D receptor agonists. Cell Immunol 233: 115-124, 2005.

13. Singh A, Kamen DL. Potential benefits of vitamin D for patients with systemic lupus erythematosus. Dermatoendocrinol 4: 146$151,2012$.

14. Holmøy T, Kampman MT, Smolders J. Vitamin D in multiple sclerosis: implications for assessment and treatment. Expert Rev Neurother 12: 1101-1112, 2012.

15. Agmon-Levin N, Kivity S, Tzioufas AG, et al. Low levels of vitamin-D are associated with neuropathy and lymphoma among patients with Sjögren's syndrome. J Autoimmun 39: 234-239, 2012.

16. Fulop M, Mackay M. Renal tubular acidosis, Sjögren's syndrome, and bone disease. Arch Intern Med 164: 905-909, 2004.

(C) 2013 The Japanese Society of Internal Medicine http://www.naika.or.jp/imonline/index.html 